\title{
Impact of A Maternal and Newborn Health Results Based Financing Intervention (RBF4MNH) On Stillbirth: A Cross-Sectional Comparison in Four Districts in Malawi.
}

\section{Regina Makuluni ( $\sim$ reg.mak55@gmail.com )}

Malawi-Liverpool-Wellcome Trust Clinical Research Programme https://orcid.org/0000-0001-93685456

\section{William Stones}

University of Malawi College of Medicine

\section{Research article}

Keywords: RBF, RBF4MNH, Health

Posted Date: September 23rd, 2020

DOI: https://doi.org/10.21203/rs.3.rs-78726/v1

License: (c) (i) This work is licensed under a Creative Commons Attribution 4.0 International License. Read Full License

Version of Record: A version of this preprint was published at BMC Pregnancy and Childbirth on June 5th, 2021. See the published version at https://doi.org/10.1186/s12884-021-03867-6. 


\section{Abstract}

Background: A Results Based Financing (RBF) model for Maternal and Newborn Health, "RBF4MNH" was implemented by the Government of Malawi in four Districts, with the aim of improving health outcomes. We used this setting to examine the impact of this model on antepartum and intrapartum stillbirth, taking women's risk factors into account.

Methods: We used maternity unit delivery registers at hospitals in four districts of Malawi to obtain information about stillbirths. The result based finance for maternal and newborn health intervention was ongoing in two districts and two non-intervention districts were used for comparison. Data were extracted from the maternity registers and analyzed using STATA version 14. Logistic regression models were developed to determine crude and adjusted odds ratios for fresh and macerated stillbirth.

Results: In the study period there were 67 stillbirths among 2,772 deliveries representing 24.1 per 1,000 live births of which $52 \%(n=35)$ were fresh (intrapartum) stillbirths and $48 \%(n=32)$ were macerated (antepartum) losses. Adjusted odds ratios (aOR) for fresh and macerated stillbirth at RBF versus non-RBF sites were $2.67(95 \% \mathrm{Cl} 1.24$ to $5.57, \mathrm{P}=0.01)$ and $7.27(95 \% \mathrm{Cl} 2.74$ to $19.25 \mathrm{P}<0.001)$ respectively.Gestational age at delivery was significantly associated with stillbirths.

Conclusion: The study did not identify a positive impact of result based finance for maternal and newborn health on the reduction of both fresh and macerated stillbirths. There is a need for rigorously designed and tested interventions to strengthen service delivery with a focus on the elements needed to ensure quality of intrapartum care.

\section{Introduction}

The average global stillbirth rate in 2015 was estimated at 18.4 per 1,000 live births, from 24.7 in 2000 (25.5\% reduction) ${ }^{[1]}$ In 2015 , an estimated 2.6 million neonates were stillborn, giving a $19 \%$ decline since 2000 , with the slowest in the reduction recorded in sub-Saharan Africa. ${ }^{[1]}$ Despite this large burden of mortality, stillbirth remains low on the global policy agenda. ${ }^{[1]}$ While neonatal mortality has received increasing global attention in recent years, deaths of babies before and during labour have remained virtually invisible to policymakers, development partners and funding agencies, despite the commonalities between risk factors for stillbirth and those for neonatal mortality. ${ }^{[2]}$

The global target for stillbirth has been set at 12 per 1000 live births by 2030 against the current 18.4 per 1000 live births. ${ }^{[3]}$ Across all settings, poor quality health care is an important risk factor for stillbirth. Both the lack of access to antenatal care and quality obstetric care have been associated with increased risk of stillbirth. ${ }^{[4]}$

While improved access to and quality of antenatal care may prevent instances of antepartum fetal loss, improved obstetric care has a major role to play in prevention of intrapartum (fresh) stillbirth. In middle and low-income countries, studies have suggested that more than half of stillbirths occur in the 
intrapartum period, and these deaths are commonly attributed to avoidable factors related to inadequate

maternity care. ${ }^{[5]}$ In contrast, in developed countries, these deaths are largely antepartum; the intrapartum fetal death of an apparently healthy baby has become rare, suggesting that with adequate obstetric care, most of these stillbirths are preventable. ${ }^{[4,6]}$ In Malawi, the overall stillbirth rate is estimated at 24 per 1,000 births. ${ }^{[3,7]}$

In 2013, the Malawi government through the Ministry of Health Reproductive Health Directorate adopted the Results-Based Financing for Maternal and Newborn Health (RBF4MNH) initiative in four districts of Dedza, Ntcheu, Mchinji and Balaka. The aim of the initiative was to improve the quality of maternal and newborn care services while maintaining high service utilization in both public and selected private notfor-profit facilities. ${ }^{[8]}$ The RBF4MNH initiative includes both supply and demand-side incentives with a supply-side intervention (Performance Based Financing, PBF) that comprises financial rewards that are provided to health facilities upon attainment of a pre-defined set of indicators pertaining to clinical and organizational performance during labour, delivery, and newborn care. ${ }^{\left[{ }^{[9]}\right.}$ Demand-side interventions include financial support to pregnant women delivered through cash transfers to those delivering at the health facility for transport and other basic needs. Besides performance contracts, the RBF4MNH initiative also included an initial input component to ensure basic structural and infrastructural needs and minor building repairs are addressed. ${ }^{[10]}$ A separate set of performance incentives were set up for the District Health Management Teams (DHMT) in each of the four districts.

Apart from receiving incentives, health care workers received capacity building through training and mentorship in the provision of care to women and newborns during antenatal care, intrapartum care and postnatal care. The intervention's impact on maternal and newborn health service utilization and quality of care has been reported. ${ }^{[11]}$ Here, we undertook a comparison of intervention and non-intervention sites to assess the impact on stillbirth.

\section{Methods}

This was a quantitative cross-sectional study which used routinely collected hospital data in the referral hospitals serving the districts of Ntcheu, Dedza, Salima (Central region) and Thyolo (Southern region). These district hospitals provide a secondary level of care and serve as the referral hospitals for all the primary health centers in their respective districts. The RBF districts were purposively selected because of ready access to hospital records by the investigator. The non-RBF comparison districts were randomly selected by applying a random number table to a list of Malawi districts. The primary outcome for analysis was stillbirth, defined as a baby born with no signs of life at or after 28 weeks gestation. ${ }^{[12]}$

A power calculation to determine the sufficiency of the number of participants was performed using Open Epi version 3 resulting in sample of 2800 with a power of $90 \%$, a statistical significance level of $5 \%$. This was based on the assumption that the stillbirth rates would be 15 per 1,000 live births in the combined population of the intervention hospitals and 34 per 1,000 in the combined population in the non- 
intervention hospitals. These assumptions was based on initial scrutiny of District Health Management Information System (DHIS-2) returns.

Data were extracted from the registers which included maternal age, gravidity, gestation age, preeclampsia, birth asphyxia, low birth weight and stillbirths. These were collected using a prepared data extraction tool in the form of a register. Data were entered into Microsoft Excel and checked for accuracy, consistency and completeness. Analysis was undertaken using STATA version 14. For continuous variables, means and standard deviations were considered and presented. Logistic regression models were developed to assess whether the relationship between RBF4MNH intervention and stillbirths was confounded by other factors. The possible confounders included in the multivariable model were; low birth weight, gestation age, gravidity and pre-eclampsia, based on findings in two previous local studies. $[6,13]$

The study was approved on a waiver by the College of Medicine Research and Ethics Committee (COMREC), a Review Board of the University of Malawi and permission was granted by the Hospital authorities.

\section{Results}

We obtained 2800 records among which $28(1 \%)$ were discarded during data cleaning owing to incorrect and missing values. Of these, $0.6 \%(n=8)$ observations were dropped at RBF sites while $1.4 \%(n=20)$ observations were dropped in the non-RBF sites. .A total of 2,772 delivery records were used in the final analyses. 1,392 of the deliveries were from RBF sites representing $50.2 \%$ while 1,380 were from non-RBF sites representing $49.8 \%$.

\section{Demographic characteristics of the mothers with stillbirths}

The mean maternal age was 24 (SD: 6.66). The majority of the women (43.3\%) were aged between 25 and 34 years with only $4.5 \%$ aged below 18 years. Just under half $(47.8 \%, n=32)$ were in their first or second pregnancy.

Table 1: Demographic characteristics of the mothers with stillbirths 


\begin{tabular}{|llll|}
\hline Variable & & Frequency & Percentage \\
\hline Age (years) & Less than 18 & 3 & 4.5 \\
& 18 to 19 & 11 & 16.4 \\
& 20 to 24 & 18 & 26.9 \\
& 25 to 34 & 29 & 43.3 \\
& $35+$ & 6 & 8.9 \\
Number of pregnancies & 1 to 2 & 32 & 47.8 \\
& $3+$ & 35 & 52.2 \\
\hline Gestation age & & & \\
(Weeks) & 28 to 33 & 12 & 17.9 \\
& 34 to 36 & 10 & 14.9 \\
& 37 to 39 & 41 & 61.3 \\
& 40 to 42 & 4 & 5.9 \\
& 43 above & 0 & 0 \\
\hline
\end{tabular}

\section{Factors associated with stillbirth}

During the study period, 67 stillbirths were identified out of 2,772 deliveries. Fifty-two percent $(n=35)$ were classified as fresh (intrapartum) stillbirths while $48 \%(n=32)$ were macerated (antepartum) stillbirths. With regard to gestational age of the entire sample population, $16.7 \%(n=463)$ were preterm and $83.3 \%$ $(n=2309)$ presented at term.

There were 1,340 live births in the RBF sites and 1,365 live births in non-RBF sites representing $96.3 \%$ and $98.9 \%$ of all births respectively (Table 2 ). More stillbirths were observed in the RBF sites than non-RBF sites, thus $3.8 \%$ and $1.1 \%$ respectively $(P<0.001)$. Other bivariate associations noted were with gestational age: of the 441 preterm births, $22(4.7 \%)$ were stillbirths $(P<0.001)$ and.low birth weight: of the 263 babies who were born with low birth weight, $4.7 \%$ were stillbirths ( $P=0.01)$. We did not identify significant associations between stillbirth and other potential determinants (Table 2).

Table 2: Factors associated with stillbirth, comparison between RBF and non-RBF sites 


\begin{tabular}{|c|c|c|c|}
\hline Variable & Live (\%) & SB (\%) & P Value \\
\hline \multicolumn{4}{|l|}{ RBF } \\
\hline Yes & & 3.7 & $<0.001$ \\
\hline \multirow[t]{2}{*}{ No } & 96.3 & 1.1 & \\
\hline & 98.9 & & \\
\hline \multicolumn{4}{|l|}{ Age group } \\
\hline Below 18 & 98.8 & 1.2 & \\
\hline $18-19$ & 97.9 & 2.1 & 0.108 \\
\hline $20-24$ & 97.9 & 2.1 & \\
\hline $25-34$ & 96.4 & 3.6 & \\
\hline $35+$ & 98.2 & 1.8 & \\
\hline \multicolumn{4}{|l|}{ Gravidity } \\
\hline Primigravida & 97.9 & 2.1 & 0.256 \\
\hline $2-5$ & 97.5 & 2.5 & \\
\hline $6+$ & 96.6 & 3.4 & \\
\hline \multicolumn{4}{|l|}{ Gestation Age } \\
\hline Preterm & 95.3 & 4.7 & $<0.001$ \\
\hline Term & 98.1 & 1.9 & \\
\hline \multicolumn{4}{|l|}{ Preeclampsia } \\
\hline Yes & 100 & 0.0 & 0.528 \\
\hline No & 97.6 & 2.4 & \\
\hline Low birth weic & & & \\
\hline
\end{tabular}




$\begin{array}{llll}\text { Yes } & 95.3 & 4.7 & 0.009 \\ \text { No } & 97.8 & 2.2 & \end{array}$

Multivariate analysis was undertaken separately for stillbirths classified as fresh (Table 3 ) and macerated (Table 4). The odds of both types of stillbirth were increased at RBF relative to non-RBF sites after controlling for variables that were significant in bivariate analyses against RBF. These were preterm birth and low birth weight, resulting in an adjusted odds ratio (aOR) for fresh (intrapartum) losses of 2.67, $95 \% \mathrm{Cl} 1.24$ to $5.57, \mathrm{P}=0.01$.

Table 3: Multiple logistic regression model of RBF and other factors associated with fresh stillbirths

\begin{tabular}{|lllll|}
\hline Variable & $\begin{array}{l}\text { Category' } \\
\text { Reference group }\end{array}$ & Odds Ratio & 95\% Cl & P Value \\
RBF & Yes & 2.67 & $1.24-5.57$ & 0.010 \\
& No & & & \\
Gestation age & Preterm & 1.61 & $0.68-3.66$ & 0.29 \\
& Term & & & \\
Low birth weight & Yes & 1.63 & $0.66-4.20$ & 0.26 \\
& No & & & \\
& & & & \\
\hline
\end{tabular}

\section{Multiple logistic regression model of RBF and other factors associated with macerated stillbirths}

The odds of macerated stillbirth were 7 folds higher when a mother delivers at an RBF site (aOR=7.27) $\mathrm{Cl}$ : 2.74 to $19.25, \mathrm{P}<0.001)$. An association between gestation age and macerated stillbirth was significant, aOR 5.11 Cl: 2.20-10.07, with a p-value of $<0.001$ and adjusting for prematurity slightly increased the apparent adverse association with delivery at a RBF site (Table 4).

Table 4: Multiple logistic regression model of RBF and other factors associated with macerated stillbirths 


\begin{tabular}{|lllll|}
\hline Variable & Category' & Odds Ratio & $95 \%$ Cl & P Value \\
& Reference group & & & \\
RBF & Yes & 7.27 & $2.74-19.25$ & $<0.001$ \\
& No & & & \\
Gestation age & Preterm & 5.11 & $2.20-10.07$ & $<0.001$ \\
& Term & & & \\
Low birth weight & Yes & 1.58 & $0.65-3.99$ & 0.312 \\
& No & & & \\
& & & & \\
\end{tabular}

\section{Discussion}

We identified 67 stillbirths out of the 2,772 births analyzed from the four hospital registers representing $24 / 1,000$ live births, a burden of mortality that is closely comparable to the current national estimate..$^{[3,7]}$ The stillbirth rate identified at RBF sites was $37 / 1,000$ live births, substantially higher than at the non-RBF sites which recorded 10/1,000 live births.

Intrapartum stillbirth is considered to be a measure of the quality of intrapartum care or may reflect inadequacies in antenatal care. In this study, stillbirth was significantly more common in RBF sites compared to non-RBF sites: this would clearly represent an unintended effect of the financing intervention. According to a study done in Malawi which was exploring intended and unintended effects of PBF, it was found that apart from positive impact of PBF on service delivery, unintended effects may occur owing to implementation realities. These include health system factors such as inadequate human resources to cater for the increased service load induced by the intervention. ${ }^{[14]}$ The observed increase in the number of stillbirths at RBF sites could also have resulted from improved documentation and record keeping which was an emphasis in the RBF program that was absent at non RBF sites. As an illustration, it was more difficult to locate registers at the non RBF sites.

The proportion of FSB (52\%) which are intrapartum deaths is higher than that of MSB (48\%). These findings are consistent with a study done in southern Africa, with much higher overall stillbirth rates, where $50 \%$ or more of the losses were intrapartum. ${ }^{[15]}$ In The Gambia findings were similar and were attributed to non-use of partograph and obstetric complications during intrapartum period. ${ }^{[16]}$ In an evaluation of RBF4MNH impact in the four RBF interventions districts in Malawi, there was no effect observed on the clinical performance of labor monitoring and partograph documentation. The study reported that the proportion of the partograph monitored cases with complete partograph documentation was $52 \% .{ }^{[8]}$ This finding justifies the observed trend in the fresh stillbirths as the evaluation showed no effect on intrapartum care which is key to newborn outcomes especially fresh stillbirth, and may discount 
the possibility that the apparent adverse association could be entirely a result of improved record keeping.

Previous systematic reviews have found that the most common factors associated with stillbirth in low resource countries were the lack of adequate antenatal care, lack of a skilled attendant at delivery, low socio-economic status, poor nutrition, previous stillbirths and advanced maternal age. ${ }^{[17-19]}$ In the RBF4MNH evaluation study, utilization rates for other maternal care services, specifically timely first ANC and at least 4 ANC visits, was found to stagnate at very low levels. ${ }^{[8]}$ In Nigeria, over half (57.0\%) of the mothers with stillbirths had no antenatal care. ${ }^{[20]}$ Although evidence supporting a direct and linear relationship between antenatal care and stillbirth is lacking, the increase in proportion of stillbirths in the RBF sites could also be attributed to low ANC utilization as reported in the RBF final results. ${ }^{[8]}$ Antenatal care can potentially serve as a platform to deliver interventions to improve the quality maternal care and early detection of risk factors that may lead to stillbirths. ${ }^{[21]}$ Several factors beyond those explored in this study could also have contributed to the increase in the number of stillbirths in the RBF facilities. These factors include increase in service utilization due to incentives given leading to pressure of work, hence affecting quality of care given to the mother during labour and delivery. ${ }^{[8]}$

In this study, a majority of the stillbirths were recorded in the mothers aged between 25 to 34 years with the least being recorded in adolescents below the age of 18 . Although age did not show any statistical significance and trends, other subgroups have potentially programmatic significance. For example, a study conducted in Ghana reported that the lifetime risk of stillbirth was $40 \%$ higher among adolescents as compared to older mothers. ${ }^{[22]}$ Similarly, a multicountry study conducted to describe the pregnancy outcomes among adolescent mothers reported that a high risk of stillbirth was found among all adolescent age groups, but the risk was significant only among adolescent mothers aged 16-17 years. ${ }^{[23]}$ However, the finding of no association of stillbirths with age observed in this study is likely to reflect the small numbers in this group and should not detract from messages that adolescent reproductive health should remain a priority for both national governments and the global health community.

Preterm birth was significantly associated with stillbirth (33\%) and this was observed at both RBF and non-RBF sites. A referral hospital based study in Malawi also found preterm birth as a factor associated with stillbirth, and recorded $67 \%$ of stillbirths who were preterm. ${ }^{[13]}$ The variations in the reported percentages could be due to the difference in study design and the setting. but overall the link between stillbirth risk and preterm birth is an established one. ${ }^{[24]}$ Thus, increasing attention to interventions to prevent preterm birth and stillbirth, alongside increasing investment for the health and wellbeing of mothers, will accelerate progress for these maternal, fetal, and newborn outcomes.

We found no positive impact of RBF on stillbirth despite the interventions targeting the quality care of for women both antenatally and during labour. In Mozambique, Pakistan, and India, a large study also showed no impact on stillbirth of a very large community intervention. ${ }^{[25]}$ These programme experiences illustrate how complex a challenge prevention of stillbirth is, as components addressing population-level 
risk factors and the fine detail of maternity care arrangements across the continuum and especially at the critical time of labour and delivery all need to converge in an effective manner. In some settings the approach has given positive results: in Rwanda where the pay for performance intervention which is similar to RBF there was an increase in utilization and quality of maternal and child care services. ${ }^{[26]}$ In Bangladesh, a pay for performance strategy in $\mathrm{MNH}$ improved the volume of services provided although it did not address the quality of care. ${ }^{[27]}$ Generally with RBF, improvements have been observed in terms of increase in the service utilization but to a lesser extent on quality.

\section{Conclusion And Recommendations}

In conclusion, the findings of this study have shown that positive effects of RBF4MNH on stillbirth could be identified. These findings highlight the need to re-focus interventions onto quality of care and close some gaps in the program implementation of RBF with regard to stillbirth prevention, notably intrapartum care arrangements. We consider that fresh stillbirth is a useful marker for intrapartum care hence an intervention should focus on it as a key indicator. Large scale programmatic investment should be underpinned by rigorous implementation research.

Recording of FSB and MSB in the Health Management Information System ((DHIS-2) would enable routine capture of data from the districts for monitoring, planning and implementation of programs targeting care during antepartum and intrapartum.

\section{Study Strengths And Limitation}

The use of cross-sectional data only allows associations to be established, but not causality. However the strength of the study was that it had a comparison group. The study results may not represent the whole population of Malawi because only a few district hospitals were considered and data collection did not include health centers. We used the traditional clinical classification of stillbirth as 'fresh' or 'macerated' in order to enable generalizability to the routine service setting where these terms are in use: this is known to be imprecise and there may well have been mis-classification between these categories. However, the main findings would not have been affected by some misclassification.

\section{Declarations}

\section{Ethical approval and consent to participate}

The study was approved by the College of Medicine Research Ethics Committee (COMREC). Since secondary data were used, no participant consent forms were included.

Consent for publication: Not applicable.

\section{Availability of data and material}


Data will be available from the authors upon request made.

\section{Competing interests}

The authors have no competing interests to declare.

\section{Funding}

This project did not have any funding.

\section{Author's contribution}

The first author had to search literature to find gaps in the area of interest, designed the study, conducted the field work and prepared the manuscript. Prof. Stones provided supervision and technical support throughout the process.

\section{Acknowledgements}

Special thanks to the directors of health services in all the districts where the study was conducted for allowing us to use the data and also midwives and data clerks for support in data collection. The statistical support from Evance Misomali is gratefully acknowledged.

\section{References}

1. Blencowe H, Cousens S, Jassir FB, Say L, Chou D, Mathers C, et al. National, regional, and worldwide estimates of stillbirth rates in 2015, with trends from 2000: a systematic analysis. Lancet Glob Health. 2016;4(2):e98-e108.

2. Lawn JE, Yakoob M, Haws RA, Soomro T, Darmstadt GL, Bhutta ZA. 3.2 million stillbirths: epidemiology and overview of the evidence review. BMC Pregnancy Childbirth. 2009;9(Suppl 1):S2.

3. The Ministry of Health in Malawi; Save the Children Malawi and UNICEF. "Every Newborn Action Plan: An Action Plan To End Preventable Neonatal Deaths In Malawi.2015.

4. McClure EM, Saleem S, Goudar SS, Moore JL, Garces A, Esamai F, et al. Stillbirth rates in low-middle income countries 2010-2013: a population-based, multi-country study from the Global Network. Reprod Health. 2015;12(2):S7.

5. McClure EM, Saleem S, Pasha O, Goldenberg RL. Stillbirth in developing countries: a review of causes, risk factors and prevention strategies. J Matern Fetal Neonatal Med. 2009 Jan;22(3):18390.

6. Metaferia AM, Muula AS. Stillbirths and hospital early neonatal deaths at Queen Elizabeth Central Hospital, Blantyre-Malawi. Int Arch Med. 2009;2(1):25.

7. National Statistical Office (NSO) [Malawi] and ICF Interna tional. Malawi Demograph ic and Health Sur- vey 2015-2016: Key Indicators Report. Zomba, Malawi and Rockville, Maryland: NSO and ICF Inter- national; 2016. 
8. Brenner S \& De Allegri M (2016). Final Results of the RBF4MNH Impact Evaluation Prepared by the Research Team Members of the University of Heidelberg and College of Medicine.

9. Kambala C, Lohmann J, Mazalale J, Brenner S, Sarker M, Muula AS, et al. Perceptions of quality across the maternal care continuum in the context of a health financing intervention: Evidence from a mixed methods study in rural Malawi. BMC Health Serv Res [Internet]. 2017 Dec [cited 2018 Sep 17];17(1). Available from: http://bmchealthservres.biomedcentral.com/articles/10.1186/s12913-0172329-6

10. Brenner CS, Allegri M De, Kambala C, Lohmann J. Final Results of the RBF4MNH Impact Evaluation. 2016; (June):1-111.

11. I B, R S, E V de P, O B, G L, F van de L, et al. Introduction of performance-based financing in burundi was associated with improvements in care and quality [Internet]. Health affairs (Project Hope). 2014 [cited 2020 Aug 25]. Available from: https://pubmed.ncbi.nlm.nih.gov/25489036/

12. WHO | Stillbirths [Internet]. WHO. [cited 2019 Sep 4]. Available from:

http://www.who.int/maternal_child_adolescent/epidemiology/stillbirth/en/

13. Chilinda G, MMed Thesis, University of Malawi 2017.pdf.

14. Petross C, McMahon S, Lohmann J, Chase RP, Muula AS, De Allegri M. Intended and unintended effects: community perspectives on a performance-based financing programme in Malawi. BMJ Glob Health. 2020 Apr;5(4):e001894.

15. Goldenberg RL, Mcclure EM, Bann CM. The relationship of intrapartum and antepartum stillbirth rates to measures of obstetric care in developed and developing countries. Acta Obstet Gynecol Scand. 2007;86(11):1303-9.

16. Jammeh A, Vangen S, Sundby J. Stillbirths in Rural Hospitals in The Gambia: A Cross-Sectional Retrospective Study [Internet]. Obstetrics and Gynecology International. 2010 [cited 2020 Apr 27]. Available from: https://www.hindawi.com/journals/ogi/2010/186867/

17. Di Mario S, Say L, Lincetto O. Risk Factors for Stillbirth in Developing Countries: A Systematic Review of the Literature. Sex Transm Dis. 2007 Jul;34(7):S11.

18. Lawn JE, Blencowe H, Waiswa P, Amouzou A, Mathers C, Hogan D, et al. Stillbirths: rates, risk factors, and acceleration towards 2030. The Lancet. 2016;387(10018):587-603.

19. Stillbirth in developing countries - McClure - 2006 - International Journal of Gynecology \&amp; Obstetrics - Wiley Online Library [Internet]. [cited 2019 Sep 1]. Available from: https://obgyn.onlinelibrary.wiley.com/doi/abs/10.1016/j.ijgo.2006.03.023

20. Olusanya BO, Solanke OA. Predictors of term stillbirths in an inner-city maternity hospital in Lagos, Nigeria. Acta Obstet Gynecol Scand. 2009 Nov 1;88(11):1243-51.

21. Bhutta ZA, Darmstadt GL, Haws RA, Yakoob M, Lawn JE. Delivering interventions to reduce the global burden of stillbirths: improving service supply and community demand. BMC Pregnancy Childbirth. 2009;9(Suppl 1):S7.

22. Yussif A-S, Lassey A, Ganyaglo GY, Kantelhardt EJ, Kielstein $H$. The long-term effects of adolescent pregnancies in a community in Northern Ghana on subsequent pregnancies and births of the young 
mothers. Reprod Health [Internet]. 2017 Dec [cited 2020 Apr 27];14(1). Available from: https://reproductive-health-journal.biomedcentral.com/articles/10.1186/s12978-017-0443-x

23. Ganchimeg T, Ota E, Morisaki N, Laopaiboon M, Lumbiganon P, Zhang J, et al. Pregnancy and childbirth outcomes among adolescent mothers: a World Health Organization multicountry study. BJOG Int J Obstet Gynaecol. 2014 Mar;121:40-8.

24. Lawn JE, Gravett MG, Nunes TM, Rubens CE, Stanton C. Global report on preterm birth and stillbirth (1 of 7): definitions, description of the burden and opportunities to improve data. BMC Pregnancy Childbirth. 2010;10(1):S1.

25. Peter von Dadelszen, Zulqar A Bhutta, Sumedha Sharma, et al. The Community-Level Interventions for Pre-eclampsia (CLIP) cluster randomised trials in Mozambique, Pakistan, and India: an individual participant-level meta-analysis. Lancet. 2020; In press.

26. Basinga P, Gertler PJ, Binagwaho A, Soucat AL, Sturdy J, Vermeersch CM. Effect on maternal and child health services in Rwanda of payment to primary health-care providers for performance: an impact evaluation. The Lancet. 2011;377(9775):1421-1428.

27. Rahman L, Rob U, Mahmud R, Alim A, Hena IA, Talukder M, et al. A pay-for-performance innovation integrating the quantity and quality of care in maternal, newborn and child health services in Bangladesh. 2011; 